Conference Poster

\title{
Analysis of Insulated-Metal-Substrates Structures in the Context of Heat Dissipation Enhancement
}

Klarmann, S., Manesh, B., Hoenle, T., Vagapov, Y.

This is a poster presented at the 7th IEEE Int. Conference on Internet Technologies and Applications ITA-17, Wrexham, UK, 12-15 September 2017

Copyright of the author(s). Reproduced here with their permission and the permission of the conference organisers.

\section{Recommended citation:}

Klarmann, S., Manesh, B., Hoenle, T., Vagapov, Y. (2017) 'Analysis of Insulated-MetalSubstrates Structures in the Context of Heat Dissipation Enhancement'. In: Proc. 7th IEEE Int. Conference on Internet Technologies and Applications ITA-17, Wrexham, UK, 12-15 September 2017, pp. 161-164. doi: 10.1109/ITECHA.2017.8101929 


\title{
Analysis of Insulated-Metal-Substrates Structures in the Context of Heat Dissipation Enhancement
}

\author{
Steffen Klarmann, Bobby Manesh \\ School of Applied Sciences, Computing and Engineering \\ Glyndwr University \\ Wrexham, LL11 2AW, UK
}

\author{
Tobias Hoenle \\ Valeo GmbH, \\ Valeostrasse 1 \\ 86650 Wemding, Germany
}

\author{
Yuriy Vagapov \\ School of Applied Sciences, Computing and Engineering \\ Glyndwr University \\ Wrexham, LL11 2AW, UK
}

\begin{abstract}
This paper discusses analysis of an insulated-metalsubstrates structure of a printed circuit board in terms of the temperature management of p-n junction of LEDs mounted on the structure's surface. The structure material and surface area are used for the heat transfer between the junction and the ambient surroundings. The heat dissipation has been simulated for conductor layer thicknesses in the range from $50 \mu \mathrm{m}$ to $200 \mu \mathrm{m}$ and the dielectric layer thicknesses from $50 \mu \mathrm{m}$ to $150 \mu \mathrm{m}$. The thermal simulation has been conducted for two base layer materials - aluminum and copper having the same thickness of $920 \mu \mathrm{m}$. The results of the simulation provide optimum thickness of the structure materials and their thermal conductivity to ensure most efficient heat dissipation.
\end{abstract}

Keywords-insulated-metal-substrates; printed circuit board; heat dissipation; LED cooling

\section{INTRODUCTION}

Visible spectrum light-emitting diodes (LEDs) are widely used for lighting and indicators [1], [2]. The main benefits of using LEDs are low heat production compared to conventional light sources, the long life span [3], [4] and the high brightness [5]. A greater LED light output can be achieved with high current flowing through the $p-n$ junction and a lower temperature of the device. Therefore, efficient LED operation requires implementation of a cooling system to prevent the device overheating and maintain the temperature at a low level [6]. The cooling is particularly crucial for high-power LED applications where the devices are operating at a luminous efficiency of about $30-40 \%$ [5]. It means that $60-70 \%$ [5] of the electrical power applied to the device is converted into heat. The temperature increase shifts the peak of wavelength generated by the p-n junction [7] and brings distortion in the light spectrum. In many applications, the dissipated heat and the peak wavelength are most important requirements. On the other hand, long overheating can significantly reduce the LED lifetime or damage the device [5], [8].

Therefore, LED-based applications require a stable and suitable operating temperature of the junction to ensure a long- lasting device lifetime and to generate the appropriate light spectrum. The cooling system employed for the direct heat dissipation from LEDs has to prevent heating influence on other electronic components allocated in the application. In many applications, the components are usually predefined and cannot be replaced. In addition, the application can be restricted regarding cooling technologies and size. The cost of the cooling system must also be taken into account at a design stage.

A typical LED installation method in mass production applications is soldering the device directly onto the surface of a printed circuit board (PCB). In such installations, PCBs can be used for both the current conduction and the heat dissipation. In recent years, various PCB structures have been developed to fit the modern electronic requirements. An improved heat transport from the device to the heat sink and surrounding area has been achieved by using insulated-metalsubstrates (IMS) PCB instead of conventional Flame Retarded 4 (FR4) PCB [8]. By optimising the IMS structure, the junction temperature of the LED can be decreased to a suitable operating temperature. This paper discusses an approach to the IMS PCB structure optimisation aimed to improve the heat transfer from the LED junction to ambient surroundings. The structure optimising was conducted using Catia FloEFD V5 simulation software. The paper also describes new IMS structures and provides comparative analysis between the new and existing materials.

Fig. 1 shows the structure of the IMS model used in this paper. Using the IMS technology, conventional surface-mount devices (SMDs) can be assembled on the copper layer. In general, an IMS PCB consists of three layers: the lower base layer, the dielectric layer in the middle, and the conductor layer on the top. The objective of the top layer is to ensure electrical connection between the devices placed on it; the top layer is the trace of the whole PCB. The materials used in IMS have to provide both an excellent electrical conductivity and an excellent thermal conductivity $(\lambda)$ for a fast heat transfer from the component to the heat sink. The function of the middle 
layer is to provide an electrical insulation between the top and bottom layer. The material of the middle dielectric layer is a chemical mixture of polymers and ceramic. The requirements applied to the IMS PCB dielectric layer are quite controversial - the layer material should provide both good electrical insulation and thermal conductivity. The bottom layer is the metal baseboard of the IMS. The main objective of this layer is to ensure a fast heat dissipation from the dielectric layer to the heat sink. Additionally, the bottom layer also acts like heat sink.

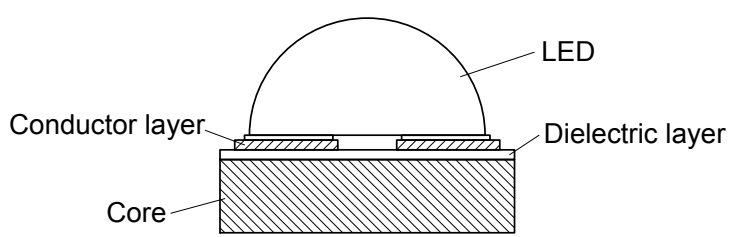

Fig. 1. LED soldered on IMS comprising of the conductor layer, the dielectric layer and the core (base layer).

\section{THERMAL RESISTANCE}

Thermal resistance is described as the temperature difference between two defined points of a material whilst experiencing a heat flow at a steady state condition [10]. Hence,

$$
R_{\mathrm{th}}=\frac{\Delta T}{q}=\frac{L}{k}
$$

where $R_{\mathrm{th}}$ is the thermal resistance, $\Delta T$ is the temperature difference; $q$ is the heat flow rate; $L$ is the thickness of the material, $k$ is the material thermal conductivity.

\section{MATHEMATICAL BACKGROUND}

The model used for IMS simulation and analysis utilises two modes of heat dissipation: conduction and convection.

\section{A. Conduction}

Conduction is a heat transfer that takes places in all solid state parts of the circuit [11]. The conductive heat flow is described by Fourier's law of heat conduction [12]:

$$
\phi_{\text {cond }}=-\lambda A \frac{\partial T}{\partial n}
$$

where $\phi_{\text {cond }}$ is the heat flow, $\lambda$ is the thermal conductivity, $A$ is the cross-section area, $\partial T / \partial n$ is the gradient of the temperature.

\section{B. Convection}

Effective convection heat transfer usually requires an extended surface or a heat sink. The convection rate can be increased using a forced air-flow over the heat sink [13]. The following equation describes the heat transfer phenomenon:

$$
\phi_{\mathrm{Qht}}=h A\left(T_{\mathrm{w}}-T_{\mathrm{f}}\right)
$$

where $\phi_{\mathrm{Qht}}$ is the rate of heat transfer, $h$ is the heat transfer coefficient, $A$ is the surface are exposed to the heat transfer, $T_{\mathrm{w}}$ is the average temperature of the surface exposed to the heat transfer, $T_{\mathrm{f}}$ is the local temperature of the fluid.
The heat sinks power dissipation is described by the following

$$
\phi_{\mathrm{Qmf}}=m c_{\mathrm{p}}\left(T_{\mathrm{e}}-T_{\mathrm{a}}\right)
$$

where $\phi_{\mathrm{Qmf}}$ is the rate of heat transfer, $m$ is the mass flow rate through the heat sink or system, $c_{\mathrm{p}}$ is the specific heat capacity of the fluid, $T_{\mathrm{e}}$ is the exit temperature of the fluid, $T_{\mathrm{a}}$ is the ambient temperature of the fluid as it enters the heat sink.

\section{Simulation}

\section{A. Model}

The ambient temperature of the simulation model was set to $T_{\mathrm{amb}}=65^{\circ} \mathrm{C}$. The PCB is rectangular with a size of $95 \mathrm{~mm} \times 19 \mathrm{~mm}$; the thickness of the samples analysed is varied. Forward voltage of SMD LEDs used for simulation is $V_{\mathrm{F}}=3.1 \mathrm{~V}$ at a forward current of $I_{\mathrm{F}}=0.445 \mathrm{~A}$. The simulated application comprises of seven LEDs required to generate a certain luminance. The total power dissipation is estimated approximately $\approx 9.66 \mathrm{~W}$. The distance between the LEDs is $4 \mathrm{~mm}$ and the heat dissipation is evenly distributed.

The path of the simulated thermal resistance is represented in Fig. 2, where the thermal resistance from junction to the solder is noted as $R_{\text {th j-s }}$, the thermal resistance from the solder to the conductor is noted as $R_{\text {th s-c }} ; R_{\text {th c-d }}$ is the thermal resistance from the conductor to the dielectric. $R_{\text {th d-core }}$ denotes the thermal resistance from the dielectric to the core material (base layer), $R_{\text {th core-hs }}$ denotes the thermal resistance from the core material to the heat $\operatorname{sink}$ and $R_{\text {th hs-amb }}$ is the thermal resistance from the heat sink to the ambient surrounding. Fig. 3 illustrates the layout of the simulated PCB with the placement of the analysed LEDs and their measuring points. A steady state heat transfer simulation was used to find the LED junction temperature $T_{j}$ for comparative analysis.

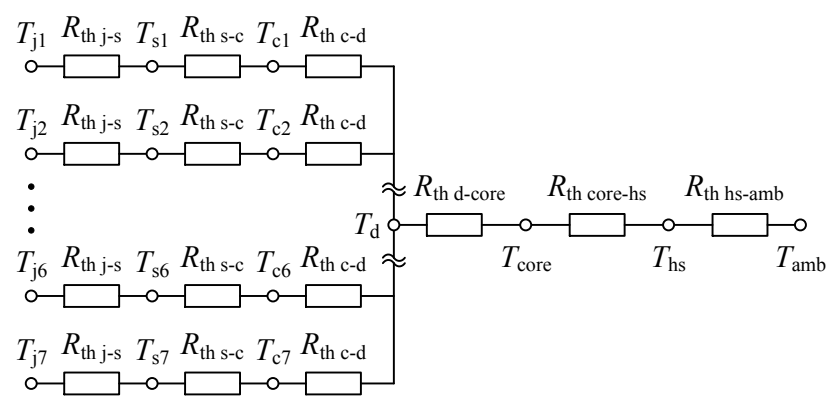

Fig. 2. Path of simulated thermal resistance

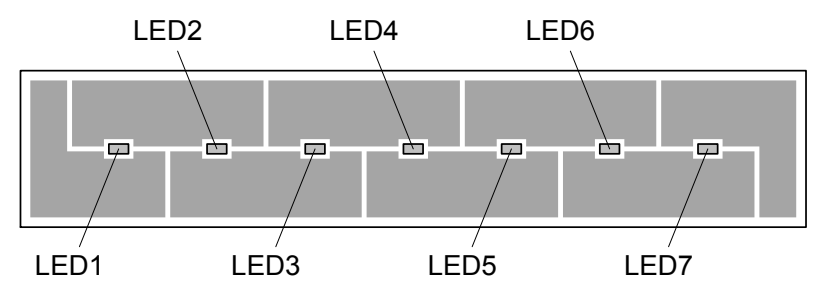

Fig. 3. IMS PCB layout with placement of the LEDs 


\section{B. Initial State}

The initial state of the simulation represents a copper conductor layer $(\lambda=385 \mathrm{~W} / \mathrm{m} \cdot \mathrm{K}, t=150 \mu \mathrm{m})$. The dielectric layer is made of a material with a thickness of $76 \mu \mathrm{m}$ and a thermal conductivity of $\lambda=2.2 \mathrm{~W} / \mathrm{m} \cdot \mathrm{K}$. The base layer is aluminum with a thickness of $920 \mu \mathrm{m}$ and $\lambda=138 \mathrm{~W} / \mathrm{m} \cdot \mathrm{K}$.

\section{Initial State Result}

The result of the initial state simulation is shown in Table I. It can be seen that LED4 has the highest junction temperature of $118.2^{\circ} \mathrm{C}$. This is due to the construction; LED4 is surrounded by three LEDs on both sides and therefore, the maximum junction temperature will always occur at LED4. The average junction temperature for the initial state is $117.6^{\circ} \mathrm{C}$

TABLE I. INITIAL STATE RESUlTS

\begin{tabular}{|c|c|c|c|c|c|c|}
\hline \multicolumn{7}{|c|}{$\boldsymbol{T}_{\text {junction }}{ }^{\circ} \mathbf{C}$ ) } \\
\hline LED1 & LED2 & LED3 & LED4 & LED5 & LED6 & LED7 \\
\hline 117.0 & 117.6 & 117.9 & 118.2 & 118.0 & 117.6 & 116.7 \\
\hline
\end{tabular}

\section{TABLE II. IMS SCENARIOS}

\begin{tabular}{|c|c|c|c|c|c|c|}
\hline $\mathbf{N o}$ & $\begin{array}{c}\text { Conductor } \\
\text { thickness } \\
(\boldsymbol{\mu m})\end{array}$ & $\boldsymbol{\lambda}_{\mathbf{c}}$ & $\begin{array}{c}\text { Dielectric } \\
\text { thickness } \\
(\boldsymbol{\mu m})\end{array}$ & $\boldsymbol{\lambda}_{\mathbf{d}}$ & $\begin{array}{c}\text { Base } \\
\text { thickness } \\
(\boldsymbol{\mu m})\end{array}$ & $\boldsymbol{\lambda}_{\mathbf{b}}$ \\
\hline 2 & 50 & 385 & 50 & 1 & 920 & 138 \\
\hline 3 & 100 & 385 & 50 & 1 & 920 & 138 \\
\hline 4 & 150 & 385 & 50 & 1 & 920 & 138 \\
\hline 5 & 200 & 385 & 50 & 1 & 920 & 138 \\
\hline 6 & 100 & 385 & 50 & 2 & 920 & 138 \\
\hline 7 & 100 & 385 & 100 & 2 & 920 & 138 \\
\hline 8 & 100 & 385 & 150 & 2 & 920 & 138 \\
\hline 9 & 100 & 385 & 50 & 3 & 920 & 138 \\
\hline 10 & 100 & 385 & 100 & 3 & 920 & 138 \\
\hline 11 & 100 & 385 & 150 & 3 & 920 & 138 \\
\hline 12 & 100 & 385 & 50 & 4 & 920 & 138 \\
\hline 13 & 100 & 385 & 100 & 4 & 920 & 138 \\
\hline 14 & 100 & 385 & 150 & 4 & 920 & 138 \\
\hline 15 & 100 & 385 & 50 & 5 & 920 & 138 \\
\hline 16 & 100 & 385 & 100 & 5 & 920 & 138 \\
\hline 17 & 100 & 385 & 150 & 5 & 920 & 138 \\
\hline 18 & 100 & 385 & 50 & 2 & 920 & 385 \\
\hline 19 & 100 & 385 & 50 & 3 & 920 & 385 \\
\hline 20 & 100 & 385 & 50 & 4 & 920 & 385 \\
\hline 21 & 100 & 385 & 50 & 5 & 920 & 385 \\
\hline
\end{tabular}

\section{Scenarios}

Various scenarios for the IMS materials and thickness were investigated to analyse the influence of the thickness, thermal conductivity and the material itself on the junction temperature of the LEDs. The details of all scenarios are given in Table II. The material of the conductor layer has not been changed during the simulations; in every simulated case it is copper $(\lambda=385 \mathrm{~W} / \mathrm{m} \cdot \mathrm{K})$. In contrast, the thickness of the conductor layer was ranged from $50 \mu \mathrm{m}$ up to $200 \mu \mathrm{m}$ and the thickness of the dielectric layer was varied from $50 \mu \mathrm{m}$ to $150 \mu \mathrm{m}$. The thermal conductivity of the dielectric layer is simulated in a range from $1 \mathrm{~W} / \mathrm{m} \cdot \mathrm{K}$ to $5 \mathrm{~W} / \mathrm{m} \cdot \mathrm{K}$. The thickness of the base layer is assumed to be $920 \mu \mathrm{m}$ for all simulations. The scenarios used for simulations utilised two materials for the base layer: aluminum $(\lambda=138 \mathrm{~W} / \mathrm{m} \cdot \mathrm{K})$ and copper $(\lambda=385 \mathrm{~W} / \mathrm{m} \cdot \mathrm{K})$.

\section{SUMMARY}

\section{A. Conductor Layer}

Based on simulation scenarios No. 2-5 (Table II), the influence of the conductor layer on the junction temperature of LED4 and the average junction temperature is shown in Fig. 4. It can be seen that an average junction temperature difference of $5.6^{\circ} \mathrm{C}$ is achieved if the conductor thickness is $200 \mu \mathrm{m}$ instead of $50 \mu \mathrm{m}$.

\section{B. Dielectric Layer}

The influence of the dielectric layer thickness and thermal conductivity is shown in Fig. 5. The conductor layer thickness was maintained at $100 \mu \mathrm{m}$. It can be seen that reducing the dielectric layer thickness lowers the average junction temperature. A larger dielectric layer thermal conductivity will also result in a lower average junction temperature. Therefore a $\Delta T_{\max }=-2.4^{\circ} \mathrm{C}$ for LED4 compared to the initial was achieved at $t=50 \mu \mathrm{m}$ and $\lambda=5 \mathrm{~W} / \mathrm{m} \cdot \mathrm{K}$. Representing a reduction of $T_{\max }$ of approx. $4.5 \%$ from the initial to the maximum permissible.

\section{Base Layer Material}

By comparing the base material layer against the dielectric thickness, it could be seen, that using a higher thermal conductivity base material achieves a lower average junction temperature. The difference between the analysed materials (aluminum and copper) is shown in Fig. 6. In general, the temperature difference observed between the two materials results in $\Delta T \approx 1^{\circ} \mathrm{C}$ where copper provides the lower temperatures. In this simulation, an average junction temperature $\Delta T$ of $3.6^{\circ} \mathrm{C}$ compared to the initial state was achieved by using a $50 \mu \mathrm{m}$ dielectric layer with a maximum thermal conductivity of $\lambda=5 \mathrm{~W} / \mathrm{m} \cdot \mathrm{K}$.

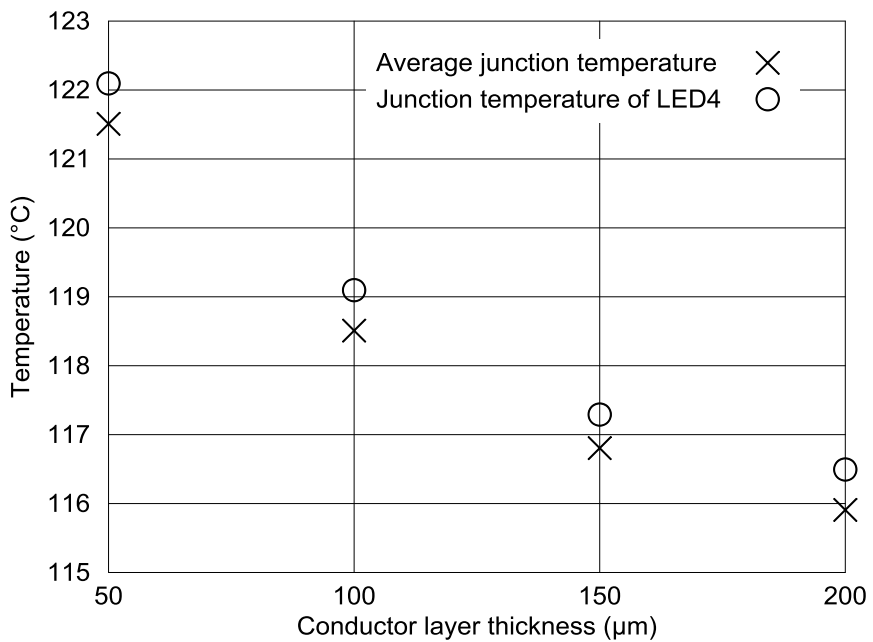

Fig. 4. Influence of the conductor layer thickness on the junction temperature of LED4 and the average junction temperature 


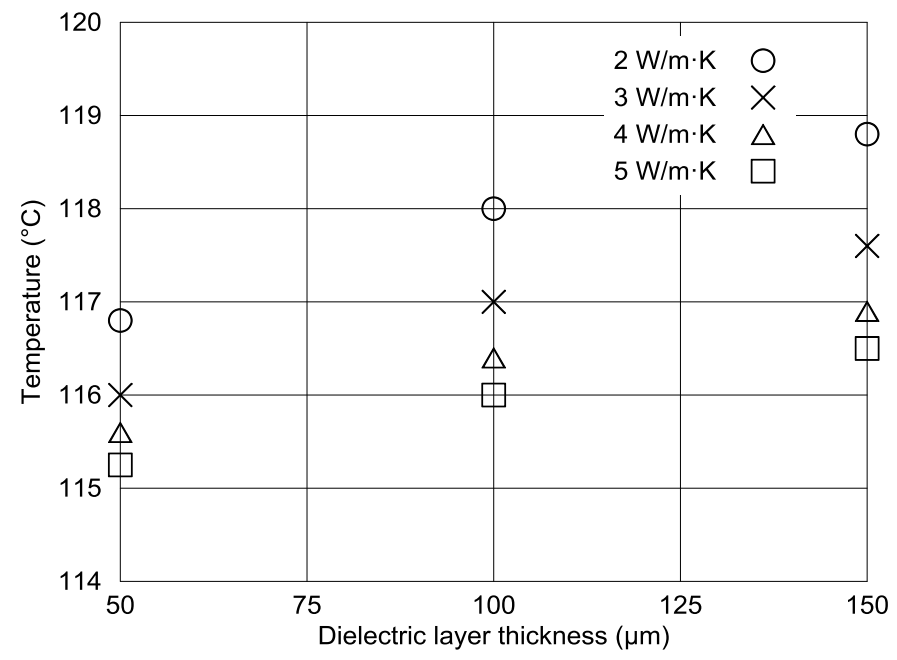

Fig. 5. Influence of the dielectric layer thickness on the average junction temperature

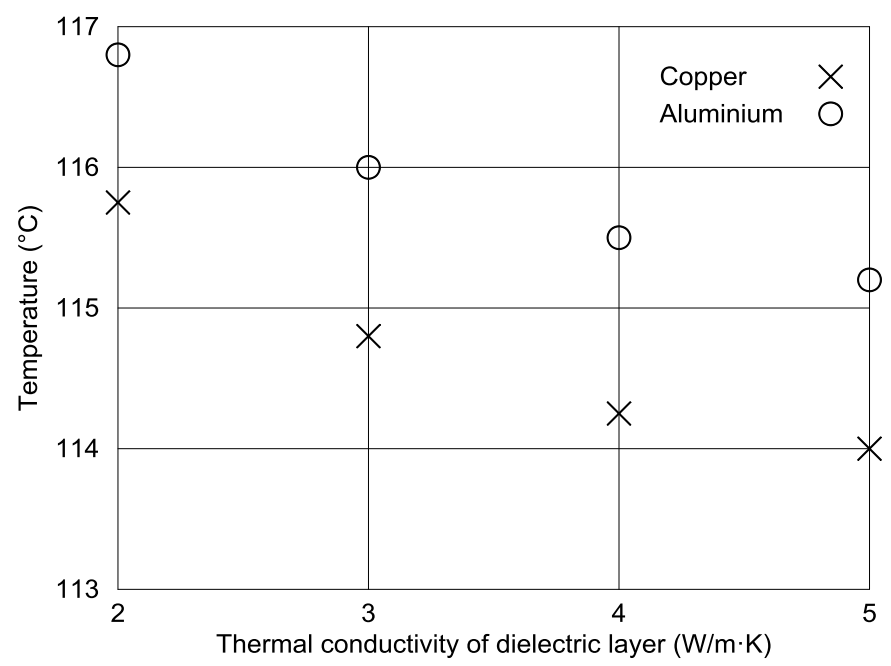

Fig. 6. Influence of the base layer material on the average junction temperature

\section{CONCLUSION}

The thermal simulation investigated an IMS PCB having conductor layer thickness in the range from $50 \mu \mathrm{m}$ to $200 \mu \mathrm{m}$. Two materials were considered for the base material: aluminum A15052 and copper. The ambient temperature of the simulation was set to $65^{\circ} \mathrm{C}$. Due to the evenly distributed heat dissipation, each LED dissipates 1.38W. The LEDs are placed on a $95 \mathrm{~mm} \times 19 \mathrm{~mm}$ IMS PCB. The primary objective is to find the ideal IMS structure regarding thermal aspects. The influence of different material properties and their thickness to the junction temperature has been analysed.

The results of the simulation demonstrated that a thicker, higher thermal conductivity base material, covered by a thinner dielectric layer with a high thermal conductivity and a thicker conductor layer would achieve the lowest junction temperature of the LEDs. However, it can be noted from the results that the reduction in average junction temperature diminishes for increasing dielectric thermal conductivity, further investigation would be required to find the best cost beneficence. The proximity of the LEDs to each other was revealed in the results to have a considerable effect on the junction temperature and must be considered for efficient heat dissipation where cost and application will allow. Compared to the initial state a maximum temperature difference $\Delta T_{\max }=2.9^{\circ} \mathrm{C}$ was achieved for a $200 \mu \mathrm{m}$ copper $(\lambda=385 \mathrm{~W} / \mathrm{m} \cdot \mathrm{K})$ conductor layer placed on a $50 \mu \mathrm{m}$ dielectric layer having a high thermal conductivity $\left(\lambda_{\max }=5 \mathrm{~W} / \mathrm{m} \cdot \mathrm{K}\right)$ and copper base material.

\section{REFERENCES}

[1] M. Arik, J. Petroski, and S. Weaver, "Thermal challenges in the future generation solid state lighting applications: Light emitting diodes," in Proc. 8th Intersociety Conf. on Thermal and Thermomechanical Phenomena in Electronic Systems, San Diego, USA, 30 May - 1 June 2002, pp. 113-120.

[2] M. E. Raypah, B. K. Sodipo, M. Devarajan, and F. Sulaiman, "Estimation of luminous flux and luminous efficacy of low-power SMD LED as a function of injection current and ambient temperature," IEEE Transactions on Electron Devices, vol. 63, no. 7, pp. 2790-2795, July 2016.

[3] A. V. Ortega, and I. N. Silva, "Neural network model for designing automotive devices using SMD LED," International Journal of Automotive Technology, vol. 9, no. 2, pp. 203-210, April 2008.

[4] J. K. Lin, "Structure of surface mount device light emitting diode," US Patent 20040099875, 27 May 2004.

[5] J.-H. Cheng, C.-K. Liu, Y.-L. Chao, and R.-M. Tain, "Cooling performance of silicon-based thermoelectric device on high power LED," in Proc. 24th International Conference on Thermoelectrics, Clemson, USA, 19-23 June 2005, pp. 53-56.

[6] C. Biber, "LED light emission as a function of thermal conditions," in Proc. IEEE 24th Annual Semiconductor Thermal Measurement and Management Symp., San Jose, USA, 16-20 March 2008, pp. 180-184.

[7] Y. Gu, and N. Narendran, "A non-contact method for determining junction temperature of phosphor-converted white LEDs," in Proc. SPIE 3rd Int. Conf. on Solid State Lighting, San Diego, USA, 3 Aug. 2003, vol. 5187, pp. 107-114.

[8] N. Narendran, and Y. Gu, "Life of LED-based white light sources," Journal of Display Technology, vol. 1, no. 1, pp. 167-171, Sept. 2005.

[9] J. Formanek, and J. Jakovenko, "Thermal characterization and lifetime prediction of LED boards for SSL lamp," Radioengineering, vol. 22, no. 1, pp. 245-250, April 2013.

[10] R. Luo, X. Li, Q. Tang, and W. Zhang, "The thermal contact resistance testing method study of thin film materials," in Proc. Conf. on Prognostics and System Health Management, Beijing, 21-23 Oct. 2015, pp. 1-5.

[11] S. Kandlikar, S. Garminella, D. Li, S. Colin, and M.R. King, Heat Transfer and Fluid Flow in Minichannels and Microchannels. Amsterdam: Elsevier, 2006.

[12] L. Qi, G. Zhang, and Y. Liu, "Modeling and simulation of the thermal network in a space gear-bearing system," in Proc. IEEE Int. Conf. on Information and Automation, Harbin, China, 20-23 June 2010, pp. 201205.

[13] R. Mahalingam, “Air cooling for LED lighting," in Thermal Management for LED Applications, Solid State Lighting Technology and Application Series, C. J. M. Lasance, and A. Poppe, Eds. New York: Springer, 2014, pp. 267-268. 